\title{
A Novel Sliding Mode Control Technique for Indirect Current Controlled Active Power Filter
}

\author{
Juntao Fei, Tianhua Li, Feng Wang, and Wanru Juan \\ Jiangsu Key Laboratory of Power Transmission and Distribution Equipment Technology, \\ College of Computer and Information, Hohai University, Changzhou 213022, China \\ Correspondence should be addressed to Juntao Fei, jtfei@yahoo.com
}

Received 14 November 2011; Revised 10 January 2012; Accepted 10 January 2012

Academic Editor: Zheng-Guang Wu

Copyright (C) 2012 Juntao Fei et al. This is an open access article distributed under the Creative Commons Attribution License, which permits unrestricted use, distribution, and reproduction in any medium, provided the original work is properly cited.

\begin{abstract}
A novel sliding mode control (SMC) method for indirect current controlled three-phase parallel active power filter is presented in this paper. There are two designed closed loops in the system: one is the DC voltage controlling loop and the other is the reference current tracking loop. The first loop with a PI regulator is used to control the DC voltage approximating to the given voltage of capacitor, and the output of PI regulator through a low-pass filter is applied as the input of the power supply reference currents. The second loop implements the tracking of the reference currents using integral sliding mode controller, which can improve the harmonic treating performance. Compared with the direct current control technique, it is convenient to be implemented with digital signal processing system because of simpler system structure and better harmonic treating property. Simulation results verify that the generated reference currents have the same amplitude with the load currents, demonstrating the superior harmonic compensating effects with the proposed shunt active power filter compared with the hysteresis method.
\end{abstract}

\section{Introduction}

With the development of modern industry, a variety of nonlinear and time-varying electronic devices such as inverters, rectifiers, and switching power supplies are widely used. These solid-state converters inject harmonics into the grid and lead to serious distortion of the power supply current and voltage, decreasing the quality of power supply. Power quality problems endanger the safe operation of the power supply and electrical equipment seriously, attracting more and more attention in the modern society [1]. Shunt active power filter (APF) is an effective device to compensate the harmonic currents in power system. The models of active power filter have been established using various methods, and the behavior of reference signal tracking has been improved using advanced control approaches. Singh et al. [2] compared two types of current control techniques, and showed that active power filter 
with indirect current control technique had simpler structure and better harmonic treating effect than direct current control. Active power filter using indirect current control method is designed in $[3,4]$, where the power supply current harmonics with sliding mode control was calculated in [3], and indirect current control technique did not need compensation current measurement, but only detection devices for power supply voltage, power supply current and DC voltage in [4]. Therefore, such technique can effectively reduce system requirement for the hardware environment and is easy to implement with DSP technique. Matas et al. [5] succeeded in linearizing the mathematical model of active power filter with feedback linearization method. The reference currents tracking behavior were improved with novel sliding mode control, reducing the power supply current harmonic content obviously in [6, 7]. Stanciu et al. [6] added integral portion to traditional hysteresis control method and reduced the steady tracking error by the designed sliding mode controller. Cheng et al. [7] adopted sliding mode control method based on proportion switch function in the controller and analyzed the robustness and stability of the system by the simulation analysis. Singh et al. [8] designed a simple fuzzy logic-based robust active power filter to minimize the harmonics for wide range of variation of load current under stochastic conditions. Rahmani et al. [9] introduced an experimental design of a nonlinear control technique for three-phase shunt APF. Chang and Shee [10] proposed novel reference compensation current strategy for shunt APF control. Montero et al. [11] compared some control strategies for shunt APF in three-phase four-wire systems. Švec et al. [12] proposed cooperative control of active power filters without mutual communication. Miret et al. [13] designed analog quasi-steady-state nonlinear current-mode controller for single-phase active power filter.

Sliding mode control technique, which combines design and analysis closely, has robustness for model uncertainty as well as external disturbance. The sliding mode controller is composed of an equivalent control part that describes the behavior of the system when the trajectories stay over the sliding manifold and a variable structure control part that enforces the trajectories to reach the sliding manifold and prevent them leaving the sliding manifold. Therefore, it is a suitable control method for reference current tracking of active power filter. Sliding mode control methods with application to active power filter have been developed in $[14,15]$, where harmonic series compensators in power systems using sliding mode was presented in [14], and adaptive discrete-time sliding mode control strategy was introduced in [15].

In this paper, a novel sliding mode control method is designed to implement the reference current tracking in the indirect current control. Two closed-loops are designed, one is the DC voltage controlling loop and the other is the reference current tracking loop. The outer voltage controlling loop with a PI regulator is used to control the DC voltage close to the given voltage of capacitor, in the current tracking loop. In the reference current tracking loop, a novel integral sliding mode controller is implemented to tracking the reference currents, thus improving harmonic treating performance. The contribution of this paper can be summarized as the following.

(1) The advantage of using novel sliding mode controller for the shunt active power filter with indirect current control technique is that it does not need harmonic detection component, but supply grid voltage sensors, filter capacitor voltage sensor and supply line current sensors. Compared with direct current control technique, it has simpler system structure and better harmonic treating performances therefore, it is easy to implement with digital signal processing system. 


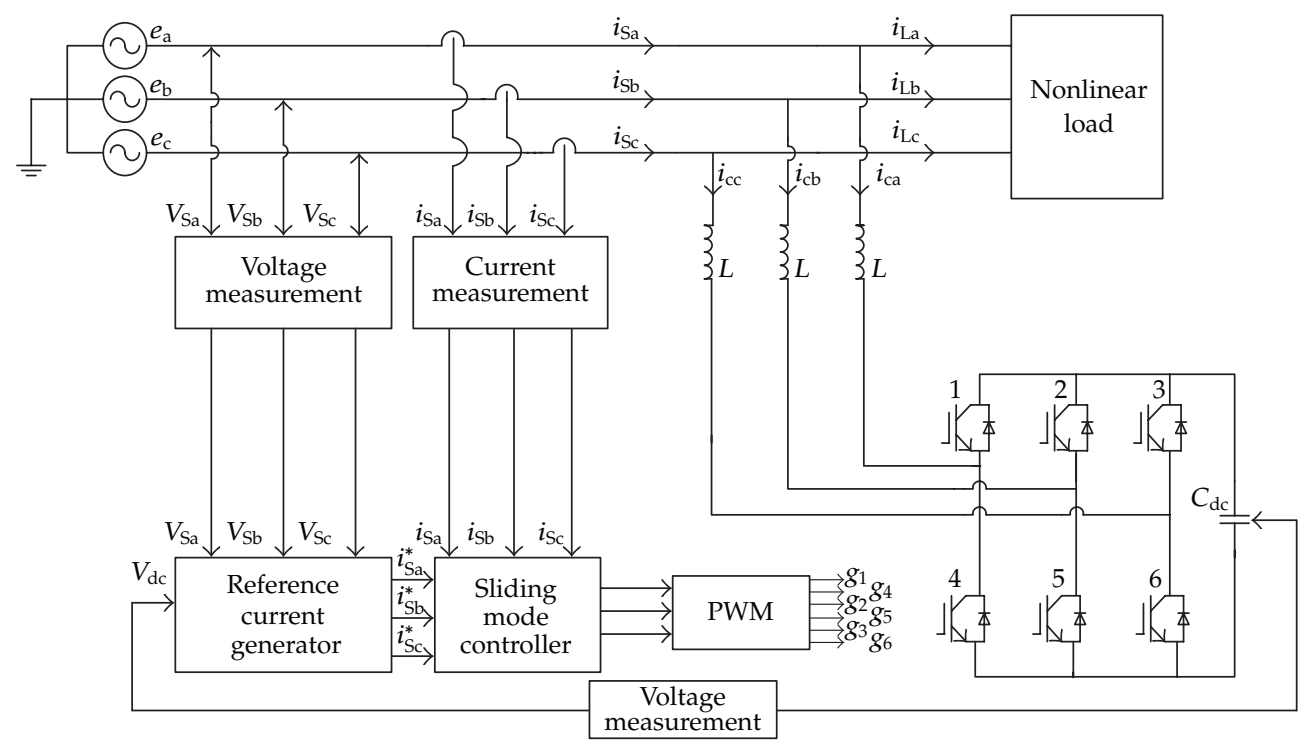

Figure 1: Schematic block diagram of shunt active power filter with indirect current control technique.

(2) A novel integral sliding mode control is proposed in reference current tracking to reduce the tracking error. A PI regulator combined with a low-pass filter is used to generate the amplitude of the reference currents. The designed active power filter has superior harmonic treating performance and minimizes the harmonics for wide range of variation of load current under difference nonlinear load; therefore, the proposed control scheme yields an improved THD performance compared with the hysteresis method.

\section{Indirect Current Control}

The schematic block diagram of shunt active power filter is shown as Figure 1. It is supposed that IGBT is an ideal switch equipment of inverter part in the shunt active power filter for the convenience of analysis; in other words, we ignore the death time and the equivalent resistance, invert rise time in "on" and fall delay time in "off."

The system consists of the following modules.

\section{(1) Compensating Currents Generator}

Compensating currents generator can generate currents which have the same amplitude and opposite phase with the harmonic currents to offset the harmonic components in the power supply current.

\section{(2) Reference Currents Generator}

The DC voltage is controlled by a PI regulator whose output is applied as the input of power supply reference current $I_{\mathrm{Sp}}^{*}$. The power supply reference currents should have the same phase with the power supply voltage, so the unit sinusoidal signals $(\sin (w t), \sin (w t+$ $\left.\left.120^{\circ}\right), \sin \left(w t-120^{\circ}\right)\right)$ can formed with phase-locked loop (PLL). Thus, supply reference currents $\left(i_{\mathrm{Sa}^{\prime}}^{*} i_{\mathrm{Sb}}^{*}, i_{\mathrm{Sc}}^{*}\right)$ can be obtained by multiplying $I_{\mathrm{Sp}}^{*}$ and the unit sinusoidal signals. 


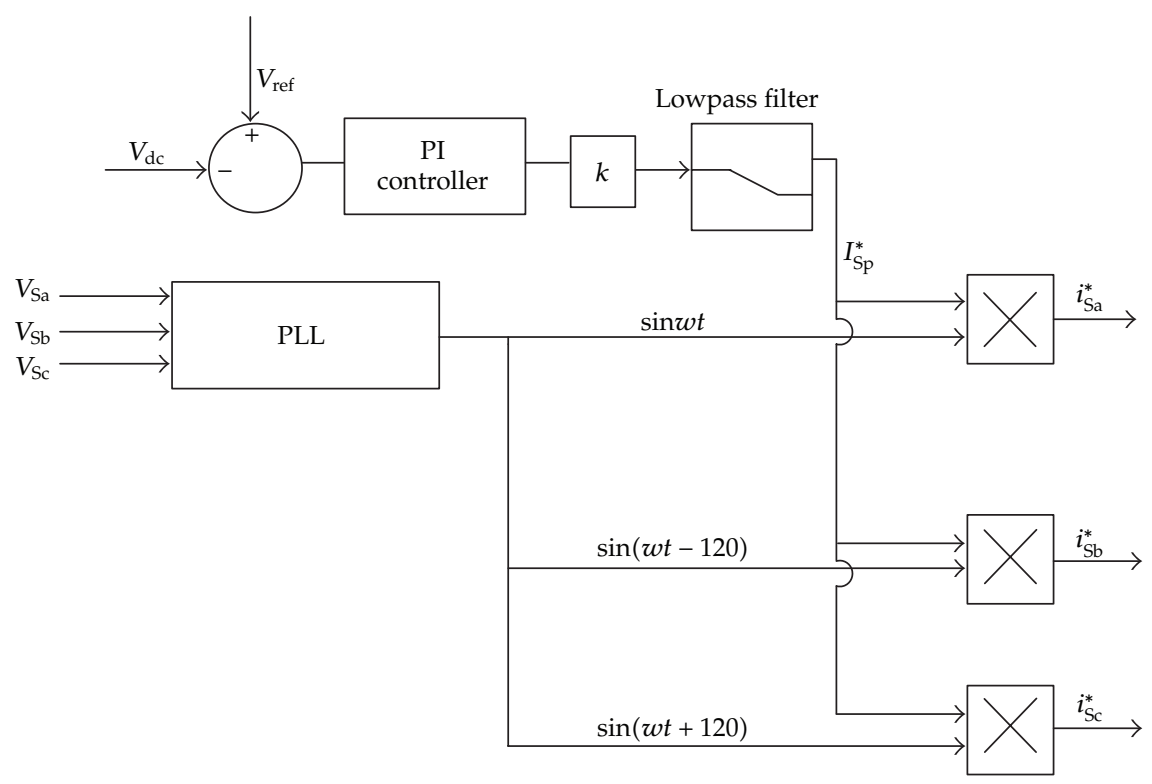

Figure 2: Schematic of the reference currents generator.

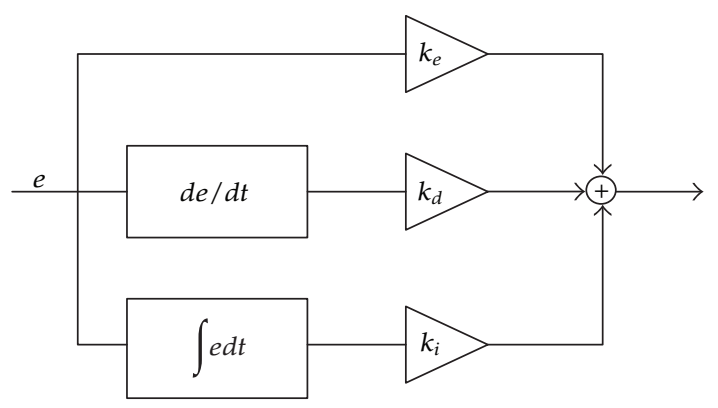

Figure 3: Schematic of the sliding mode control.

\section{(3) Sliding Mode Controller}

In this module, a novel position tracking sliding mode control technique is applied. The output of sliding mode controller is used to generate PWM signals $\left(g_{1}, g_{2}, g_{3}, g_{4}, g_{5}, g_{6}\right)$ which control the status of IGBT "on" or "off."

\section{(4) Measuring Devices}

This module contains devices for measuring supply voltages, supply currents, and DC voltage. 


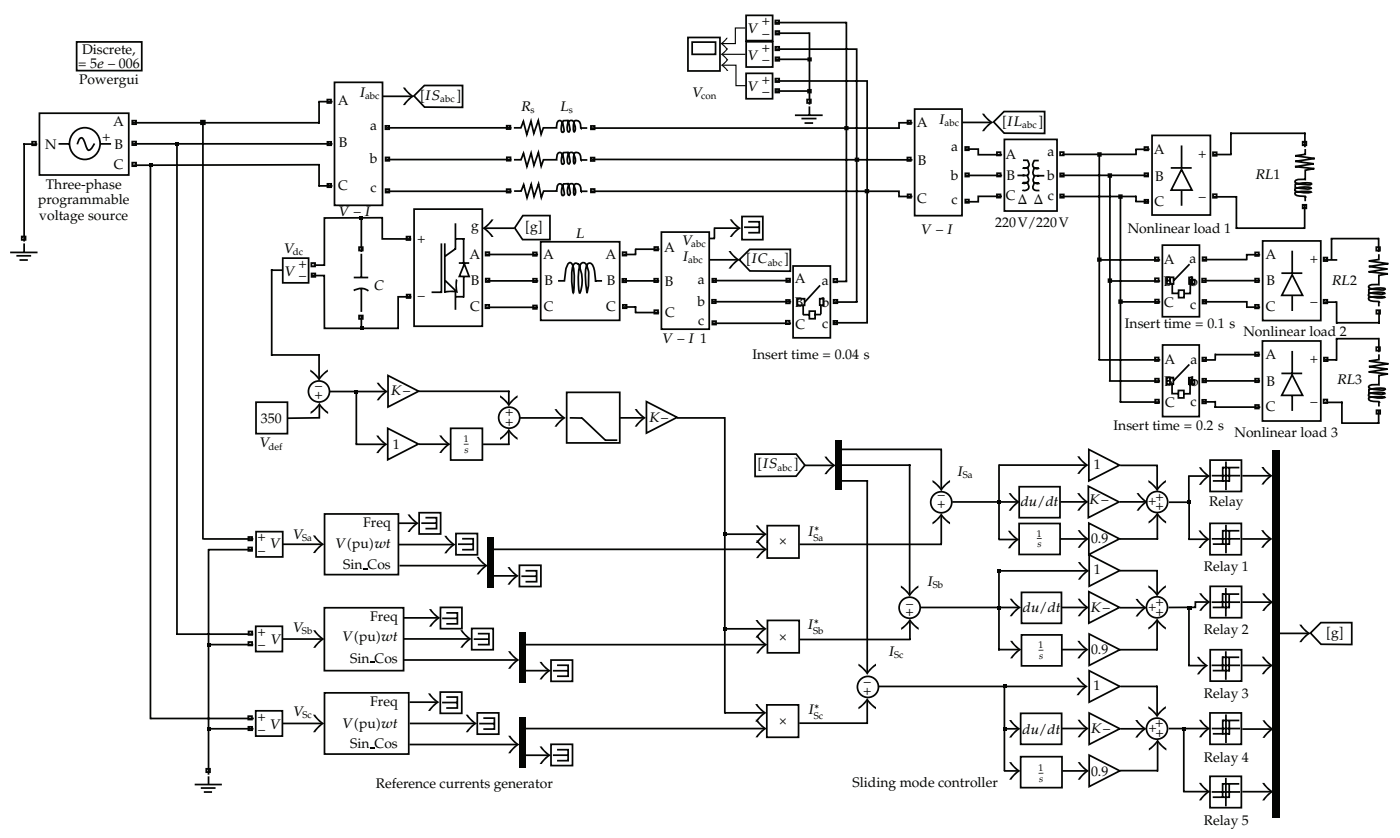

Figure 4: Simulink block diagram of APF.

\subsection{Model of the Three-Phase Three-Wire Active Power Filter}

Define $\left(i_{\mathrm{Sa}}, i_{\mathrm{Sb}}, i_{\mathrm{Sc}}\right)$ as the supply currents, $\left(i_{\mathrm{La}}, i_{\mathrm{Lb}}, i_{\mathrm{Lc}}\right)$ as the load currents, $\left(i_{\mathrm{ca}}, i_{\mathrm{cb}}, i_{\mathrm{cc}}\right)$ as the compensating currents. According to the Kirchhoff's current law, we can deduce the relation as follows:

$$
\begin{aligned}
& i_{\mathrm{Sa}}=i_{\mathrm{La}}+i_{\mathrm{ca}}, \\
& i_{\mathrm{Sb}}=i_{\mathrm{Lb}}+i_{\mathrm{cb}}, \\
& i_{\mathrm{Sc}}=i_{\mathrm{Lc}}+i_{\mathrm{cc}} .
\end{aligned}
$$

The state equations of three-phase three-wire APF

$$
\begin{aligned}
& L \frac{d i_{\mathrm{ca}}}{d t}=u_{\mathrm{Sa}}-u_{a}, \\
& L \frac{d i_{\mathrm{cb}}}{d t}=u_{\mathrm{Sb}}-u_{b}, \\
& L \frac{d i_{\mathrm{cc}}}{d t}=u_{\mathrm{Sc}}-u_{c},
\end{aligned}
$$



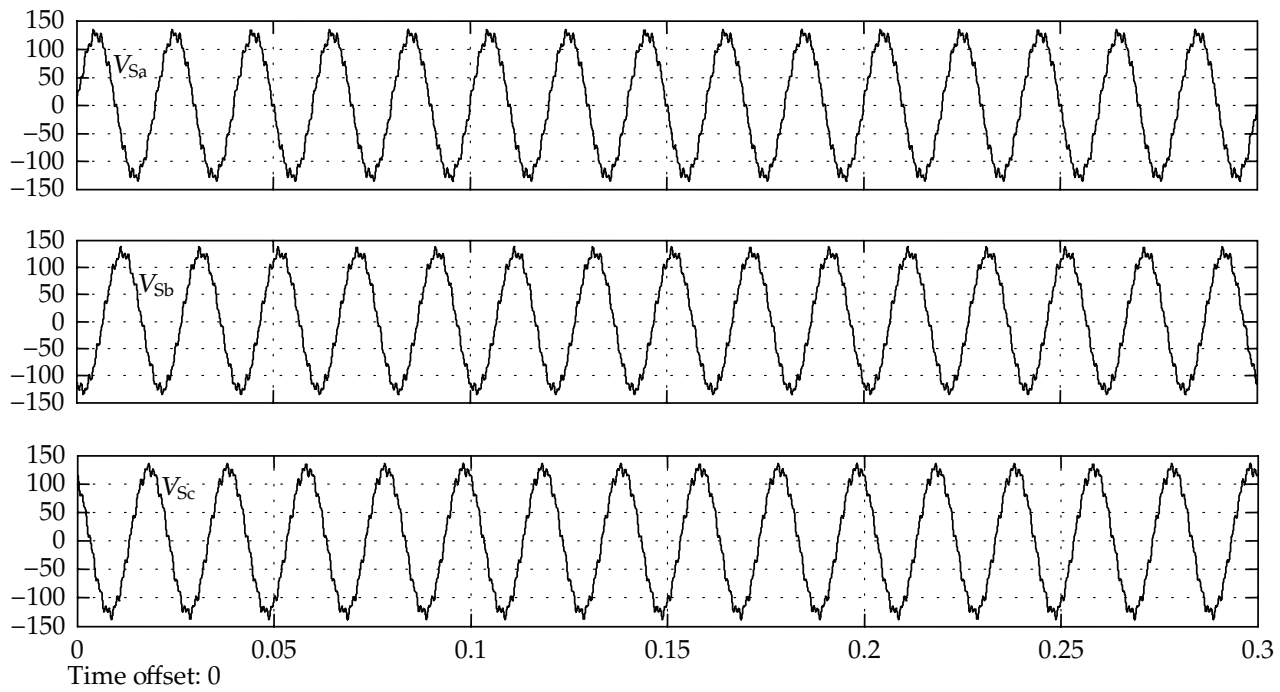

Figure 5: Waves of supply voltages.
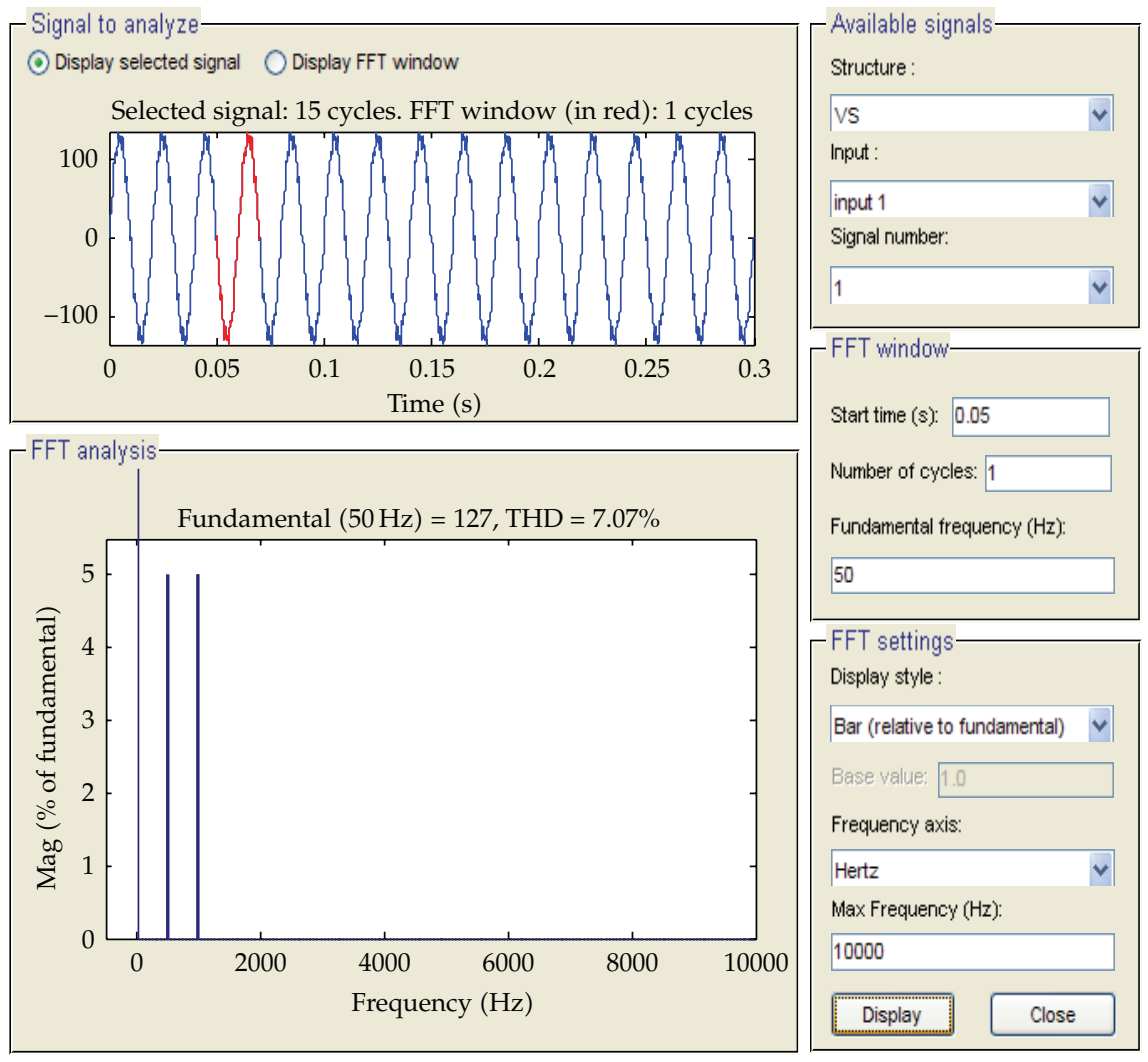

Figure 6: The THD of supply voltage. 

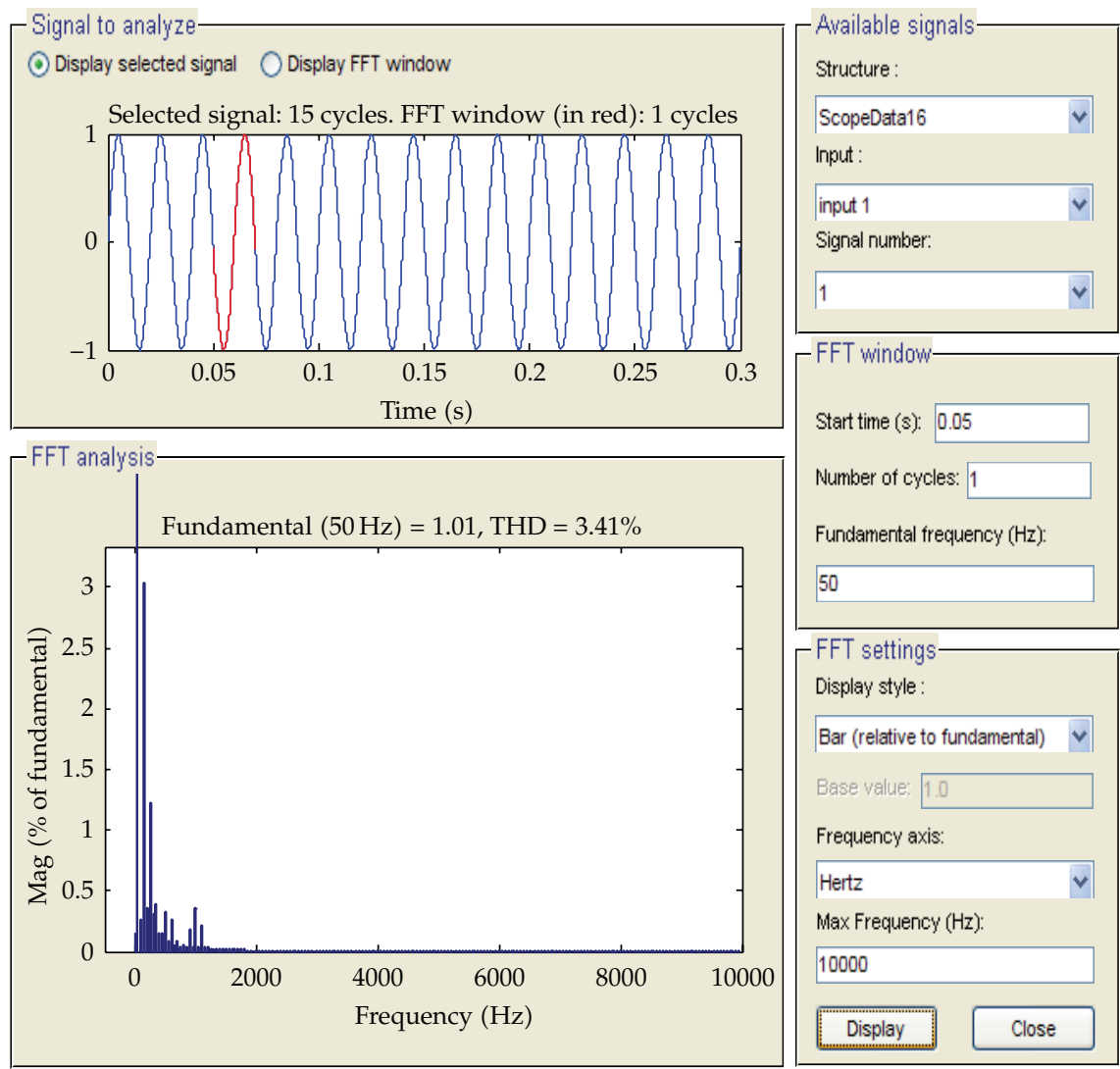

Figure 7: The THD of unit sinusoidal signals.
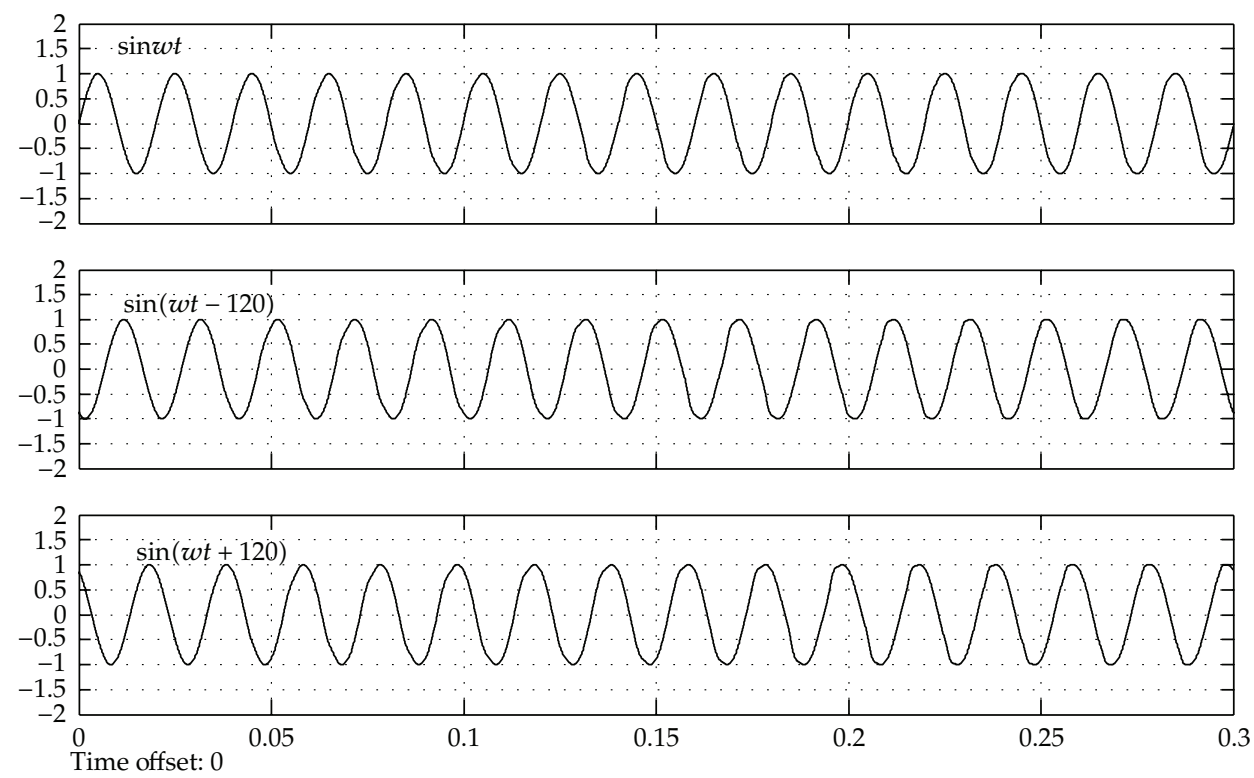

Figure 8: Waves of unit sinusoidal signals. 


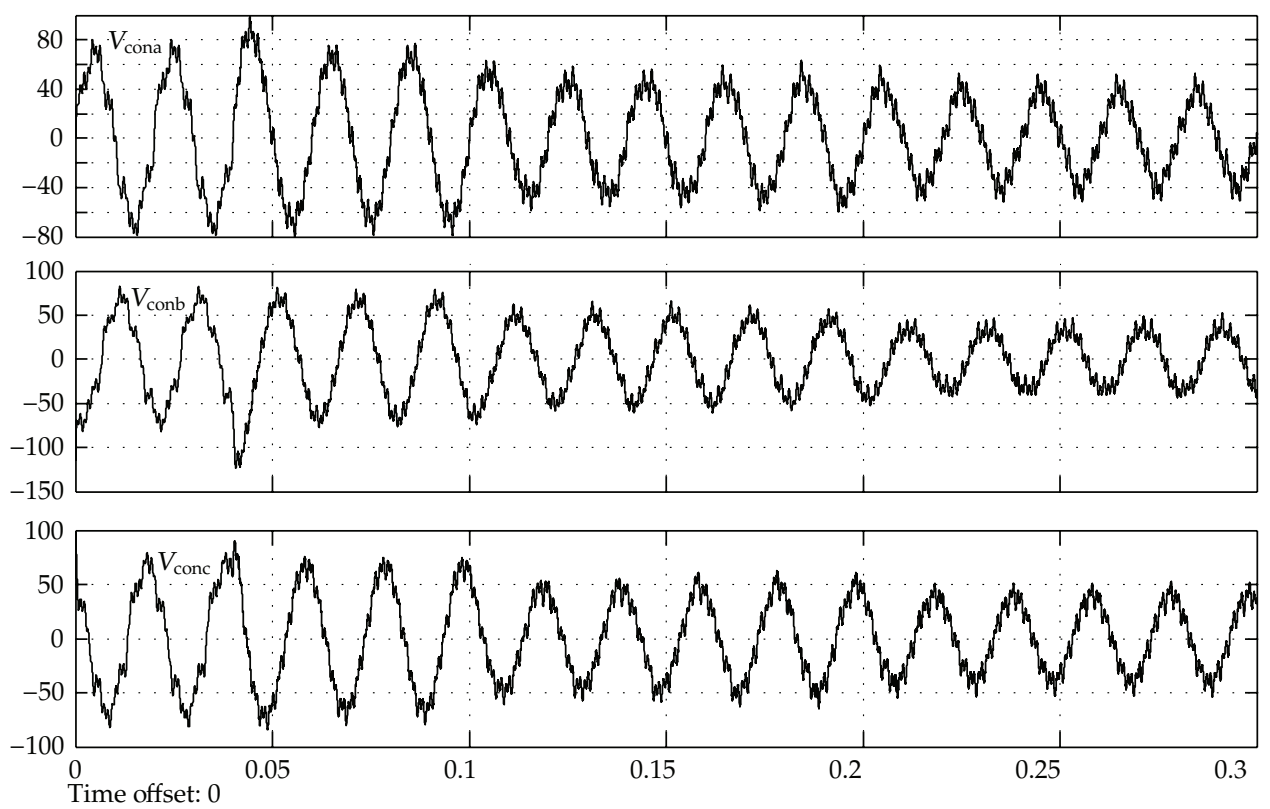

Figure 9: Waves of voltage on APF connection point.
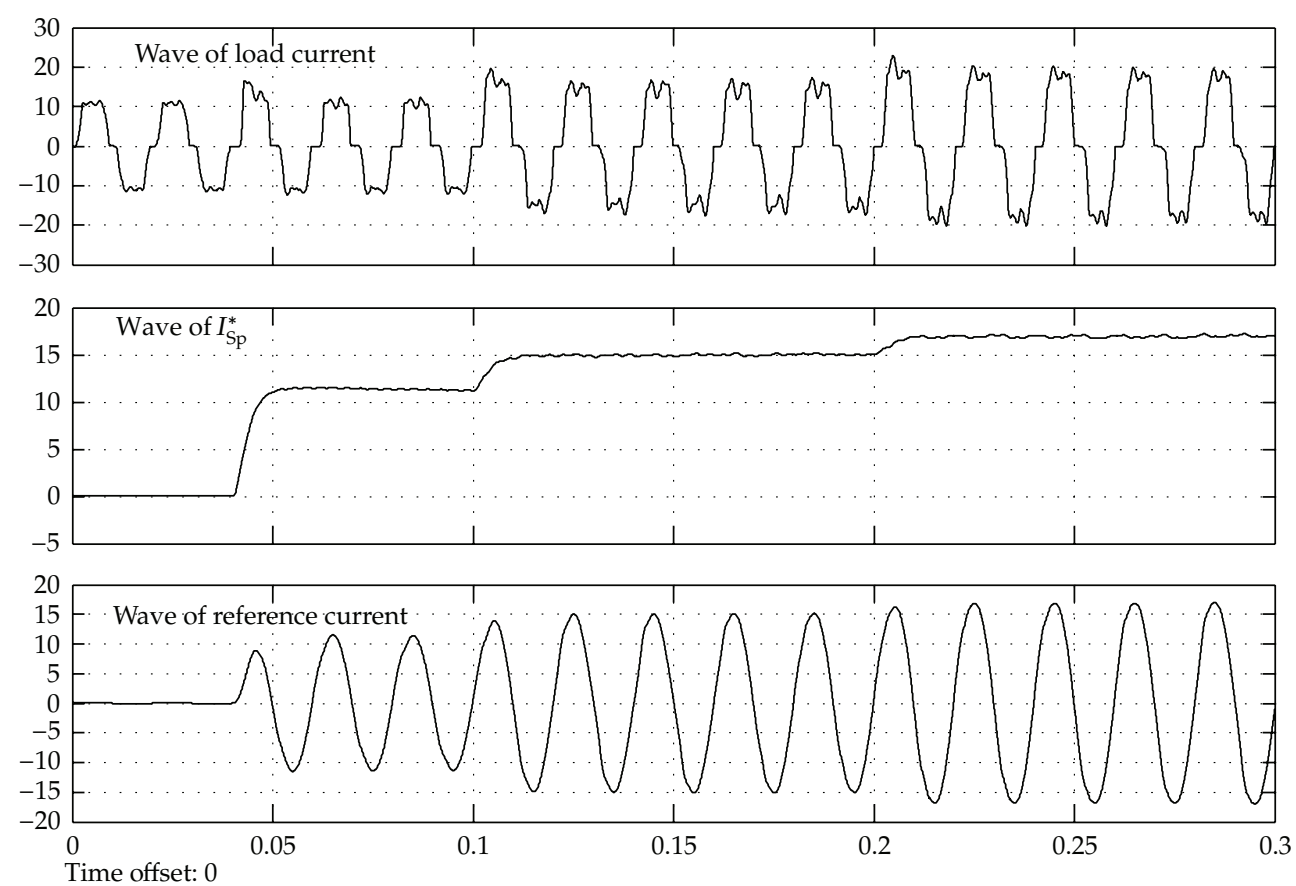

Figure 10: Waves of load current, $I_{\mathrm{Sp}}^{*}$ and A-phase reference current, in A phase. 


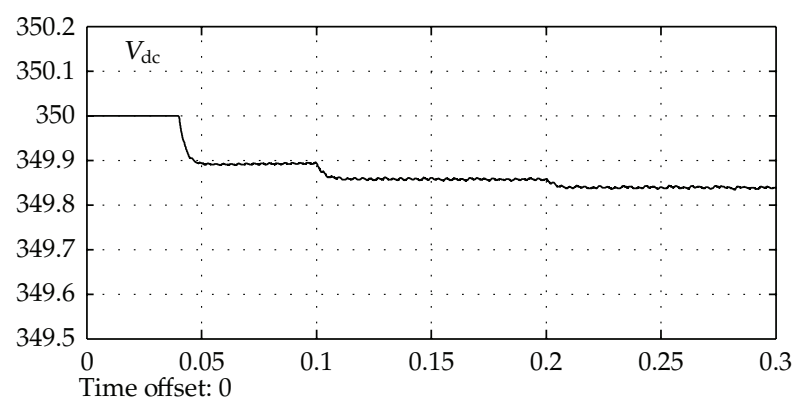

Figure 11: Waveform of the DC voltage.
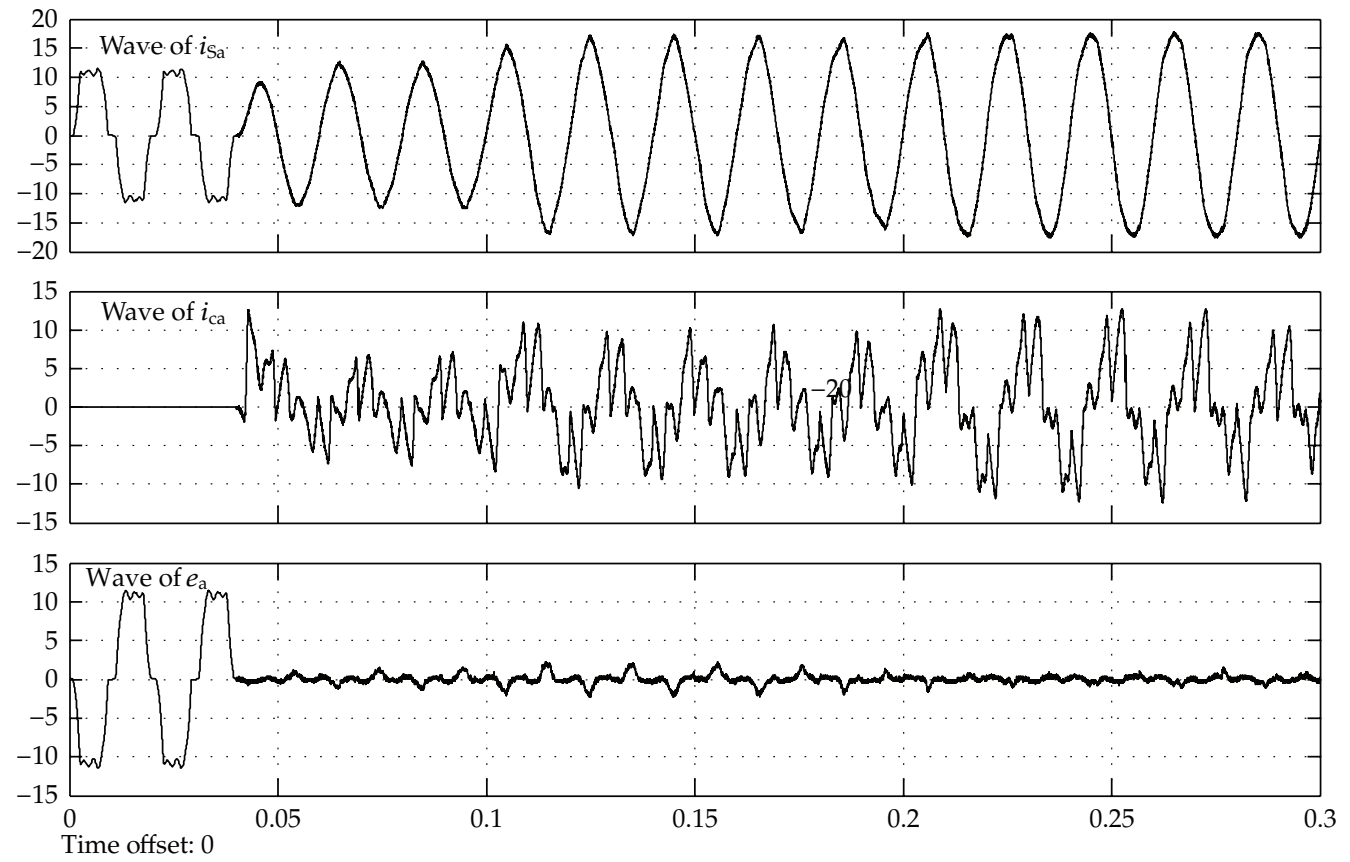

Figure 12: Waveform of the supply current, compensating current and tracking error in A phase.

where

$$
\begin{aligned}
& u_{a}=\frac{u_{\mathrm{dc}}\left(2 j_{a}-j_{b}-j_{c}\right)}{3}, \\
& u_{b}=\frac{u_{\mathrm{dc}}\left(-j_{a}+2 j_{b}-j_{c}\right)}{3}, \\
& u_{c}=\frac{u_{\mathrm{dc}}\left(-j_{a}-j_{b}+2 j_{c}\right)}{3} .
\end{aligned}
$$

The switching function $j_{i}=1$ when the IGBT of $i$-phase's upper bridge is on and the below bridge's is off. Oppositely, $j_{i}=0$ when the IGBT of $i$-phase's upper bridge is off and the below bridge's is on. 


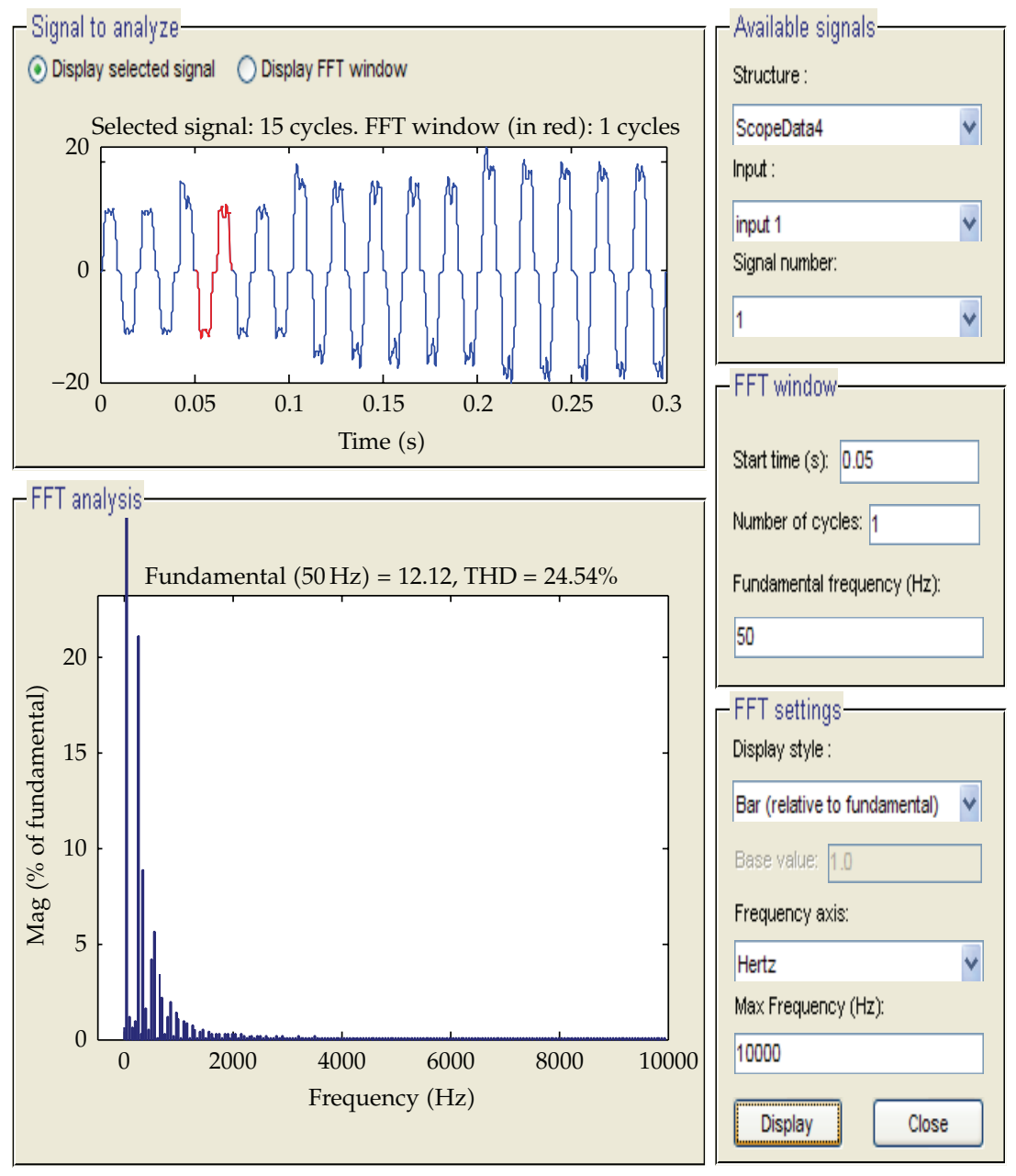

Figure 13: THD of load current.

\subsection{Reference Currents}

Reference currents $\left(i_{\mathrm{Sa}}^{*}, i_{\mathrm{Sb}}^{*}, i_{\mathrm{Sc}}^{*}\right)$ are produced from the reference currents generator. The schematic block diagram of the reference currents generator is shown as Figure 2.

The three-phase unit sinusoidal signals should have the same phase with the supply voltage, so three PLLs are used to get unit $\sin (\sin w t, \sin (w t-120), \sin (w t+120))$. The parameters of PI regulator determine the static and dynamic performance of the DC voltage. By proper parameters setting, the DC voltage can be well stabilized around the given value but not strictly equal to that value. Accordingly, the output of PI regulator is also stable. There is a fixed ratio between the PI regulator's output and load current amplitude, so $I_{\mathrm{Sp}}^{*}$ can be formed by multiplying output of PI regulator and the ratio. Otherwise, a low-pass filter is added after the PI regulator and its output which is much more stable than PI regulator's are applied as $I_{\mathrm{Sp}}^{*}$. Multiplying the unit sinusoidal signals and $I_{\mathrm{Sp}}^{*}$, the supply reference currents $\left(i_{\mathrm{Sa}}^{*}, i_{\mathrm{Sb}}^{*}, i_{\mathrm{Sc}}^{*}\right)$ can be formed. 


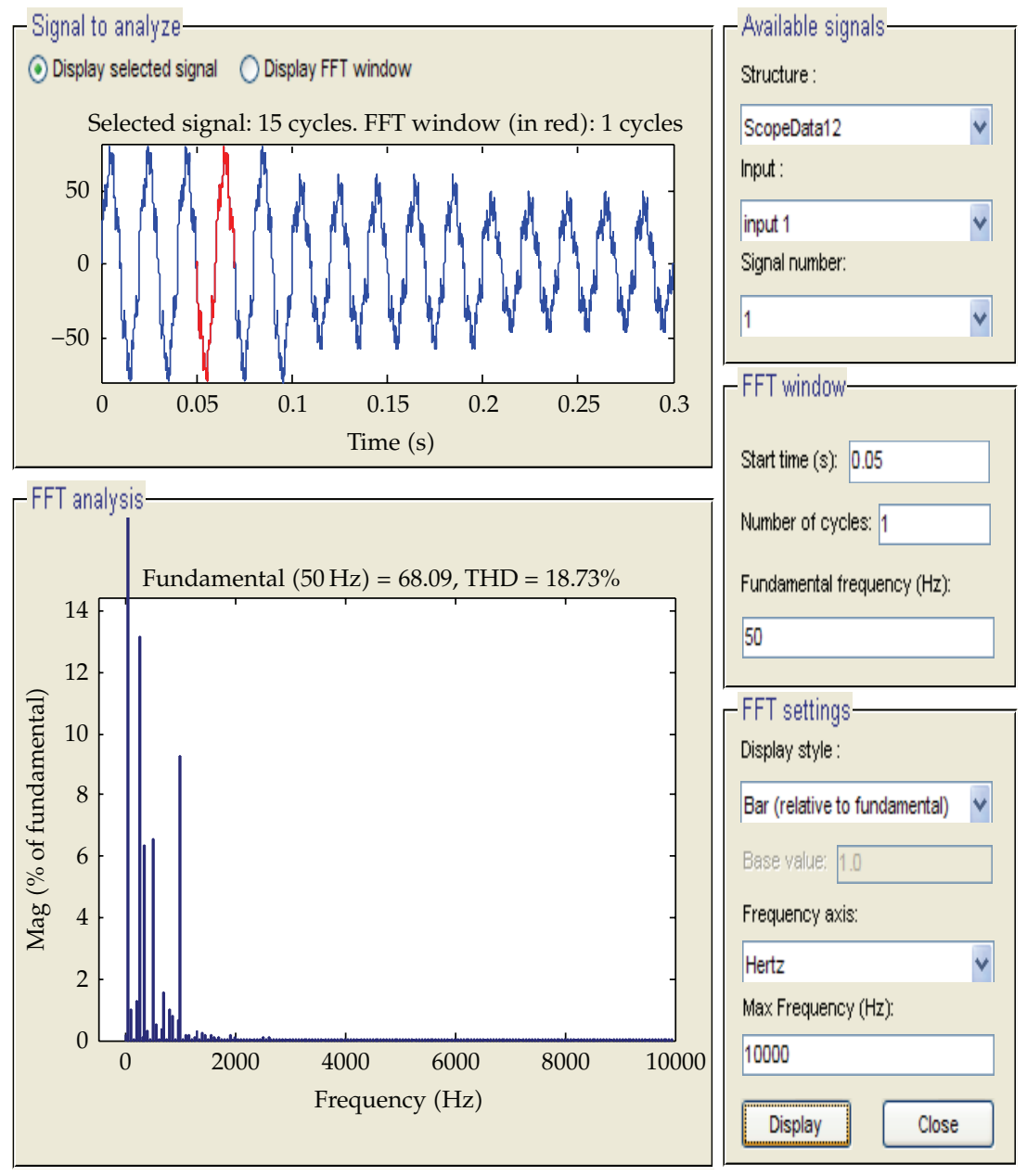

Figure 14: THD of connection point before compensating.

\section{Sliding Mode Control}

The sliding mode control theory has been widely applied in the active power filter, due to its satisfactory operation characteristics such as fastness, robustness, and stability for large load variations. According to the position tracking sliding mode control theory, we define the reference current tracking error as $e$ and the velocity error as $\dot{e}$,

$$
e=i_{S}^{*}-i_{S}, \quad \dot{e}=i_{S}^{*}-i_{S}
$$

Defining the tracking error $e$ and velocity error $\dot{e}$ as state variable, we can obtain the sliding mode surface

$$
S=C E,
$$

where $C=\left[k_{e}, k_{\mathrm{de}}\right], k_{e}>0, k_{\mathrm{de}}>0$, and $E=\left[\begin{array}{c}e \\ e\end{array}\right]$. 


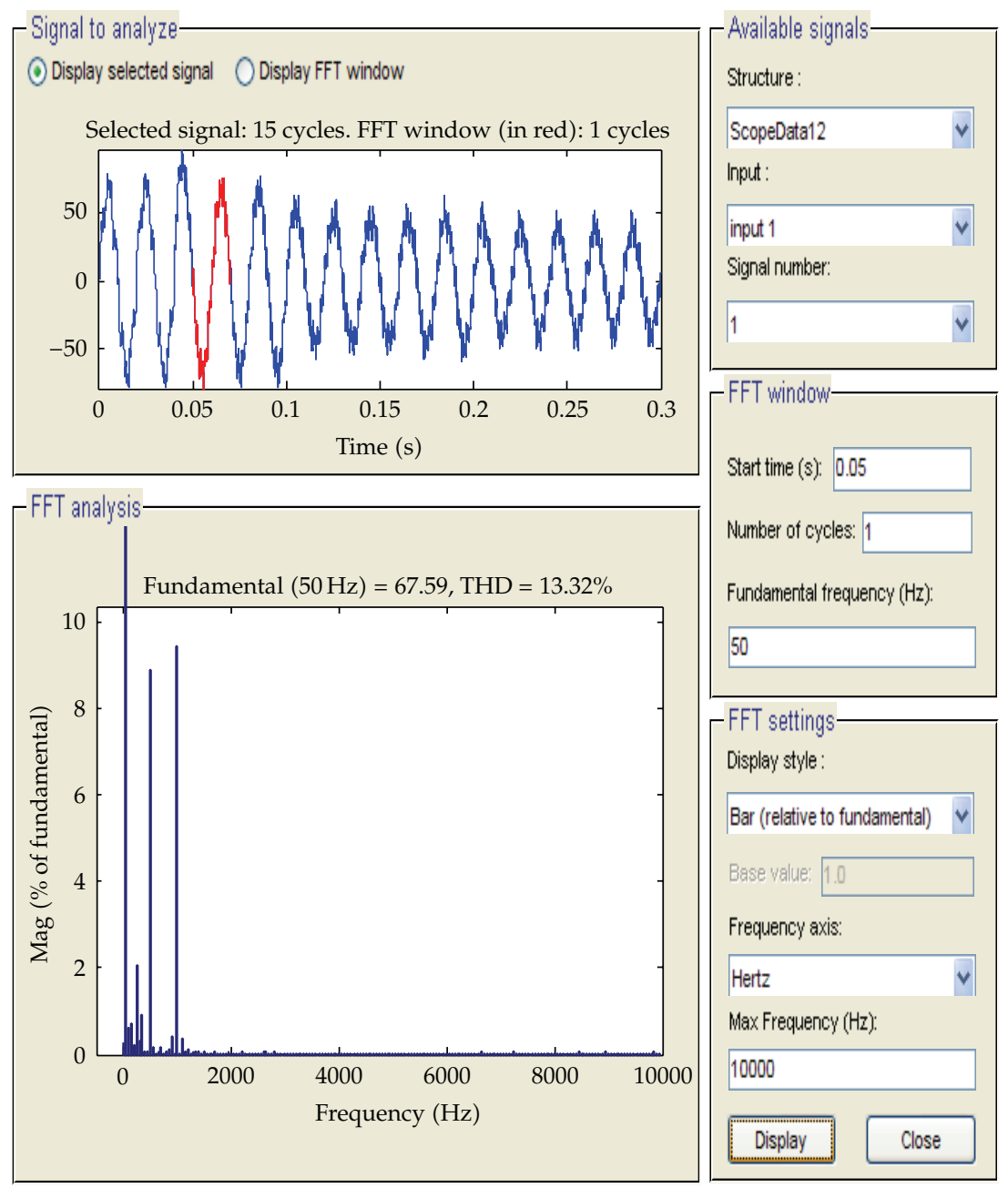

Figure 15: THD of connection point with comparison controller.

When tracking random trajectory, traditional SMC method cannot avoid steady-state error in the presence of external disturbances. In this section, an improved position tracking sliding mode control technique with an integral portion is proposed to solve this problem [16]. The switch function of the novel SMC can be described as

$$
S=k_{e} e+k_{d} \dot{e}+k_{i} \int e .
$$

The block diagram of the proposed sliding mode control is shown as Figure 3. The input is tracking error $e$ and the output of sliding mode controller is applied to generate PWM pulse signals which control IGBT "on" or "off." 


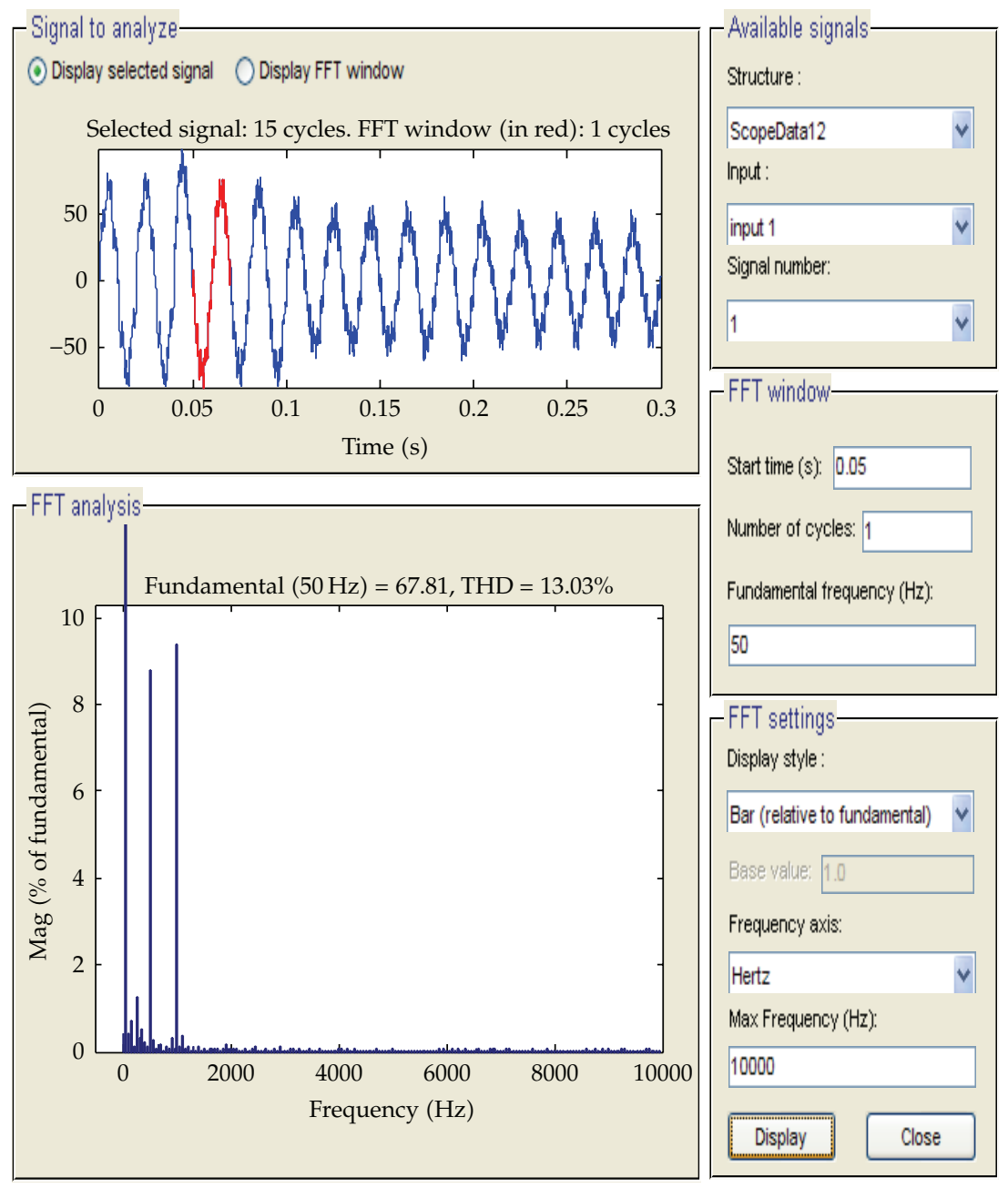

Figure 16: THD of connection point with designed sliding mode controller.

The voltage across the capacitor is stabilized by a PI regulator. The relationship between the switching function and control signal is shown as (2.3). So we can define the constant switching control

$$
u_{i}=K_{i} u_{\mathrm{dc}} \operatorname{sgn}\left(S_{i}\right), \quad \text { where } K_{i}=\frac{1}{3} \text { or } \frac{2}{3} i=a, b, c .
$$

Remark 3.1. The PI controller is designed to control DC voltage stable, but not strictly equal to the given value. As the stable error exists, the output of PI regulator is also stable. There is a fixed ratio between the output of PI regulator and amplitude of load current, even if the load currents change. The reference currents amplitude can be formed by multiplying the output of PI regulator and the ratio. It is difficult to calculate the parameters of PI regulator in mathematic way, so we merely adjust the parameter to make DC voltage stable.

The control regulation is described as Table 1 . 
Table 1: IGBT switching regulation.

\begin{tabular}{lcccc}
\hline Situation & Sa & Sb & Sc & $j_{i}$ mode \\
\hline I & + & + & - & $(1,1,0)$ \\
II & - & + & - & $(0,1,0)$ \\
III & - & + & + & $(0,1,1)$ \\
IV & - & - & + & $(0,0,1)$ \\
V & + & - & + & $(1,0,1)$ \\
VI & + & - & - & $(1,0,0)$ \\
\hline
\end{tabular}

Table 2: The components and parameters.

\begin{tabular}{lc}
\hline Supply voltage $\left(V_{s}\right)$ & $110 \sqrt{ } 2 \mathrm{~V}$ \\
Harmonic of supply voltage & $50 \mathrm{HZ}$ \\
O: Amplitude & $(10$ th and 20th) 20 \\
\hline Line's inductance \& resistance $\left(L_{s}, R_{s}\right)$ & $5 e-6 \mathrm{H} 5 \Omega$ \\
Inductance in compensator $(L)$ & $3 e-3 \mathrm{H}$ \\
DC side capacitor $(C)$ & $320 e-3 \mathrm{~F}$ \\
Given voltage of Capacitance $\left(V_{\text {def }}\right)$ & $350 \mathrm{~V}$ \\
Resistance in nonlinear load $\left(R_{L}\right)$ & $10 \Omega$ \\
Inductance in nonlinear load $\left(L_{L}\right)$ & $2 e-3 \mathrm{H}$ \\
Parameters of PI regulator $\left(K_{p}, K_{i}, K\right)$ & $100,1,1.05$ \\
Parameters of sliding mode controller $\left(k_{e}, k_{d}, k_{i}\right)$ & $1,0.9 e-5,0.9$ \\
\hline
\end{tabular}

\section{Simulation Analysis}

In this section, the active power filter system, control strategies are implemented on realistic models by using the SimPowerSystems blockset of MATLAB. The nonlinear load consists of three-phase Universal Bridge and Series RL Branch. The components and parameters are listed in Table 2.

Figure 4 is simulation block diagram of APF. The APF begins to work at the time $t=0.04 \mathrm{~s}$ when the break is closed. In practical power system, supply voltage may contain frequently varying harmonic and nonlinear loads which deteriorate the effect of harmonic compensation. In order to analyze the performance of the active power filter system, we design the voltage of supply contains 10th and 20th harmonic, and add another nonlinear load separately at the time $t=0.1 \mathrm{~s}$ and $t=0.2 \mathrm{~s}$.

As shown in Figures 5 and 6, the waves of supply voltage distort because of 10th and 20th harmonic and the total harmonic distortion (THD) is $7.07 \%$ according to the harmonic analysis. Unit sinusoidal signals should have the same phase with the power supply voltage. Figures 7 and 8 show the THD of sinusoidal signals and their waves. As the power supply voltage is not pure sinusoidal signals, unit sinusoidal signals contain harmonic. Figure 9 shows the wave of APF connection point. The switching of IGBT makes the voltage of the connection to vibrate frequently. As the switching of IGBT, the wave of connection voltages keeps buffeting with high frequency. The simulating result reveals that THD of APF connection point is also reduced. Figure 10 shows the waves of A-phase load current, $I_{\mathrm{Sp}}^{*}$ and A-phase reference current. Simulation result reveals that the average value of $I_{\mathrm{Sp}}^{*}$ is equal to that of the load current in each stage. The compensating currents are raised as the energy flowing into the LC branch while decreased as the energy flowing out, so the reference 


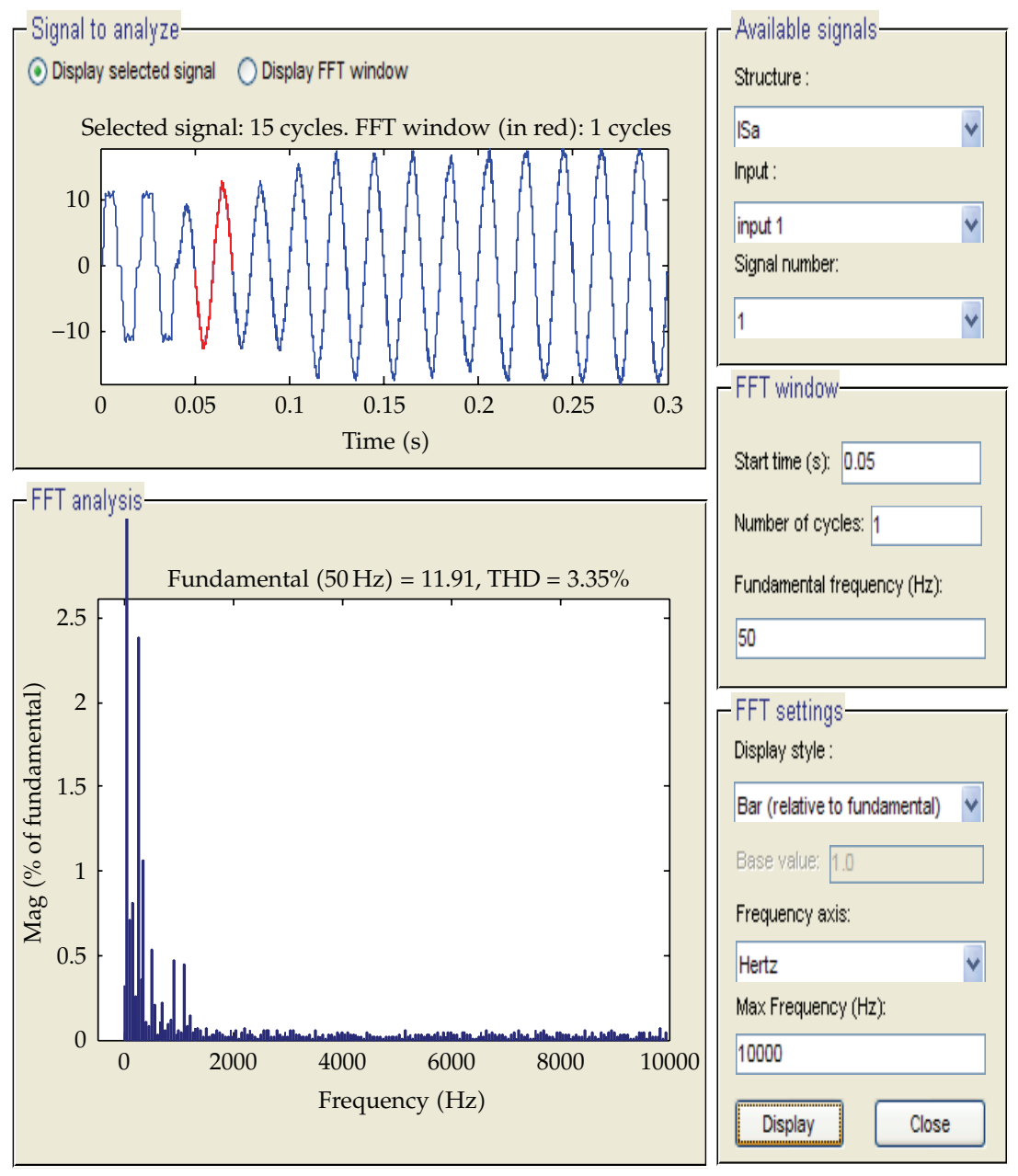

Figure 17: THD of supply current with hysteresis comparison controller.

currents have the same amplitude with the load currents that can minimize the flowing of energy and improve the stability of system as well as harmonic compensating effect. We set the initial value of the DC voltage at $350 \mathrm{~V}$ to simplify the analysis. The DC voltage is stabilized by PI regulator, but the steady error between the DC voltage and given value will increase as the load currents rise. Figure 11 is the waveform of the DC voltage. There is stable error between the DC voltage and the given value, which can be used to evaluate the amplitude of load currents. The waveforms of supply current, compensating current and tracking error in A phase are shown in the Figure 12. The formed supply currents have the same amplitude with the load currents.

The frequency range for THD evaluation (Figures 13, 14, 15, 16, and 17) is increased to 10000 in order to include HF components. Harmonic analysis results are shown from Figure 13 to Figure 18, and comparison of harmonic compensating effect between hysteresis comparison method and the designed integral sliding mode control method is also carried out. Before active power filter compensating, the THD of supply current is $24.72 \%$. The THD of supply current is reduced to $3.35 \%$ using indirect current control with hysteresis 


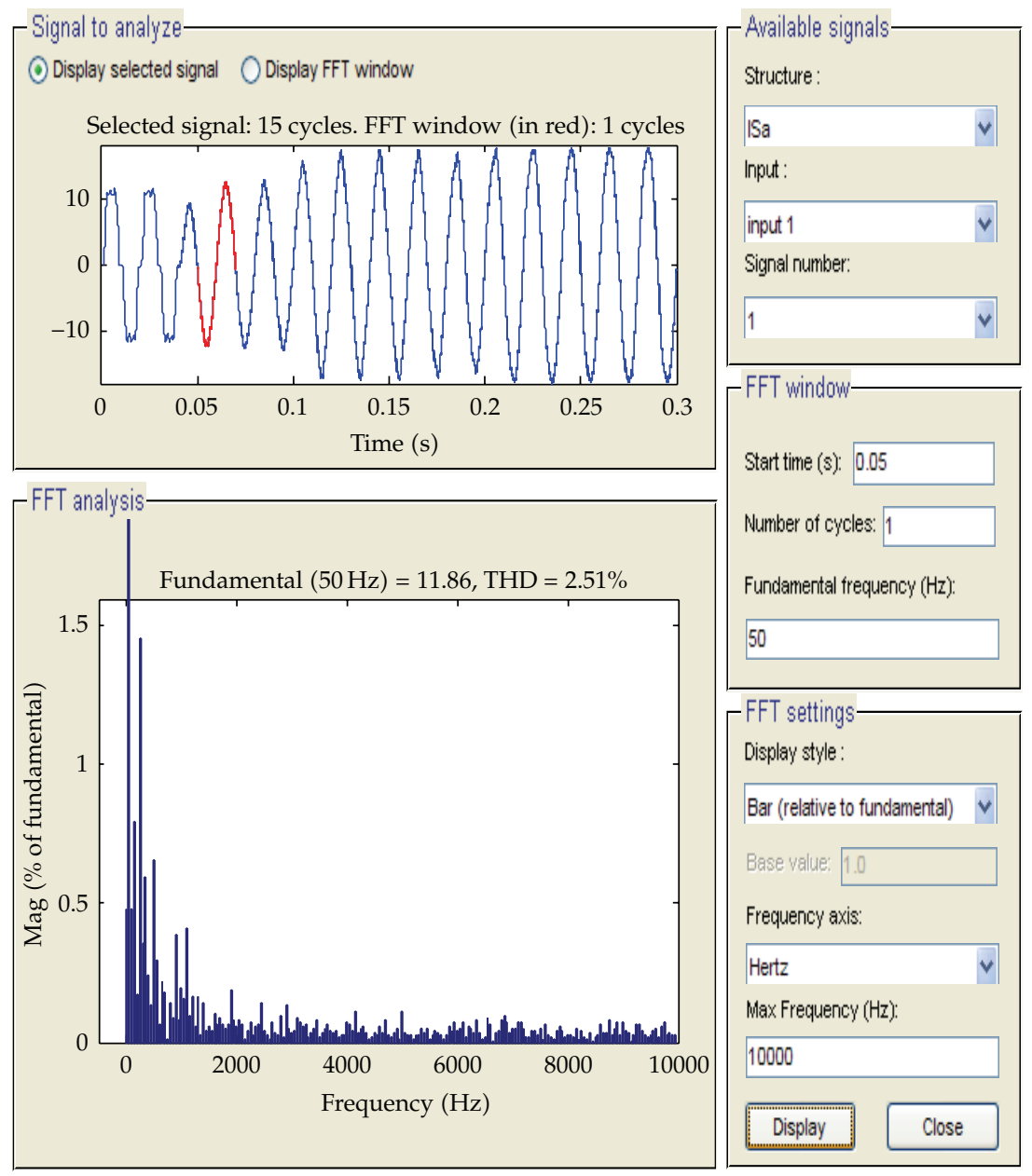

Figure 18: THD of supply current with designed sliding mode controller.

comparison method. Keeping the simulating parameters unchanged, the THD of supply current is reduced to $2.51 \%$ by applying the designed sliding mode controller. The THD of APF connection point is also reduced from $18.73 \%$ to $13.03 \%$. According to the IEC-61000 issued by IEC in the year of 2000 , harmonic content of the low voltage $(\leq 1 \mathrm{kV})$ should be under $5 \%$, so indirect current controlled active power filter with sliding mode controller has better harmonic compensating effect.

\section{Conclusion}

In this paper, a sliding mode control technique with integral portion is designed for indirect current control active power filter. This sliding mode control is applied in reference current tracking to reduce the tracking error. A PI regulator combined with a low-pass filter is used to generate the amplitude of the reference currents $I_{\mathrm{Sp}}^{*}$. Multiplying the $I_{\mathrm{Sp}}^{*}$ with unit sinusoidal signals, reference currents having the same phase with power supply voltage can be formed. Simulations under the variable system load are carried out to show the robustness 
of the active power filter system. The result reveals that the reference currents have the same amplitude with the load currents, and the designed active power filter has superior harmonic compensation effect. However, tracking error will increase when the load currents have high variance ratio. The comparative simulation shows the better reference current tracking performance of designed sliding mode control method than hysteresis comparison method. Future research direction includes the advanced control methodologies such as adaptive control and intelligent control with application to the direct current control active power filter.

\section{Acknowledgment}

The authors thank the anonymous reviewer for useful comments that improved the quality of the manuscript. This work is partially supported by National Science Foundation of China under Grant no. 61074056, The Natural Science Foundation of Jiangsu Province under Grant no. BK2010201, and The Scientific Research Foundation of High-Level Innovation and Entrepreneurship Plan of Jiangsu Province.

\section{References}

[1] Q. Jiang, D. Zhao, and J. Chen, Principle and Control of Active Power Filter, Science Press, 2005.

[2] B. Singh, A. Chandra, and K. Haddad, "Performance comparison of two current control techniques applied to an active power filter," in Proceedings of the International Conference on Harmonics and Quality of Power, pp. 133-138, Athens, Ga, USA, 1998.

[3] D. Nedeljković, M. Nemec, K. Drobnič, and V. Ambrožič, "Direct current control of active power filter without filter current measurement," in Proceedings of the International Symposium on Power Electronics, Electrical Drives, Automation and Motion (SPEEDAM '08), pp. 72-76, 2008.

[4] B. Singh, "Sliding mode control technique for indirect current controlled active power filter," in Proceedings of the Annual Technical Conference of IEEE Region 5, pp. 51-58, 2003.

[5] J. Matas, L. Garcia de Vicuna, J. Miret, J. M. Guerrero, and M. Castilla, "Feedback linearization of a single-phase active power filter via sliding mode control," IEEE Transactions on Power Electronics, vol. 23, no. 1, pp. 116-125, 2008.

[6] D. Stanciu, M. Teodorescu, A. Florescu, and D. A. Stoichescu, "Single-phase active power filter with improved sliding mode control," in Proceedings of the 17th IEEE International Conference on Automation, Quality and Testing, Robotics (AQTR '10), pp. 15-19, May 2010.

[7] B. Cheng, P. Wang, and Z. Zhang, "Sliding mode control for a shunt active power filter," in Proceedings of the 3rd International Conference on Measuring Technology and Mechatronics Automation (ICMTMA '11), vol. 3, pp. 282-285, 2011.

[8] G. K. Singh, A. K. Singh, and R. Mitra, "A simple fuzzy logic based robust active power filter for harmonics minimization under random load variation," Electric Power Systems Research, vol. 77, no. 8, pp. 1101-1111, 2007.

[9] S. Rahmani, N. Mendalek, and K. Al-Haddad, "Experimental design of a nonlinear control technique for three-phase shunt active power filter," IEEE Transactions on Industrial Electronics, vol. 57, no. 10, Article ID 5373908, pp. 3364-3375, 2010.

[10] G. W. Chang and T. C. Shee, "A novel reference compensation current strategy for shunt active power filter control," IEEE Transactions on Power Delivery, vol. 19, no. 4, pp. 1751-1758, 2004.

[11] M. I. M. Montero, E. R. Cadaval, and F. B. González, "Comparison of control strategies for shunt active power filters in three-phase four-wire systems," IEEE Transactions on Power Electronics, vol. 22, no. 1, pp. 229-236, 2007.

[12] J. Švec, J. Tlustý, J. Škramlík, and V. Valouch, “Cooperative control of active power filters in power systems without mutual communication," Mathematical Problems in Engineering, vol. 2010, Article ID 517184, 13 pages, 2010. 
[13] J. Miret, D. Garcia, and M. Matas, “Design of an analog quasi-steady-state nonlinear current-mode controller for single-phase active power filter," IEEE Transactions on Industrial Electronics, vol. 56, no. 12, pp. 4872-4881, 2009.

[14] H. De Battista and R. J. Mantz, "Harmonic series compensators in power systems: their control via sliding mode," IEEE Transactions on Control Systems Technology, vol. 8, no. 6, pp. 939-947, 2000.

[15] H. Wang, Q. Li, Y. Gong, and Y. Duan, "An adaptive sliding mode control methodology applied to shunt active power filter," in Asia-Pacific Power and Energy Engineering Conference (APPEEC '10), March 2010.

[16] J. Liu, MATLAB Simulation for Sliding Mode Control, Tsinghua University Press, 2005. 


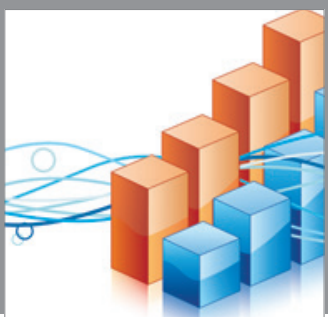

Advances in

Operations Research

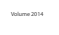

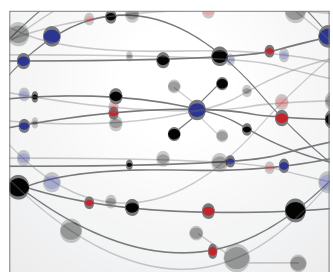

\section{The Scientific} World Journal
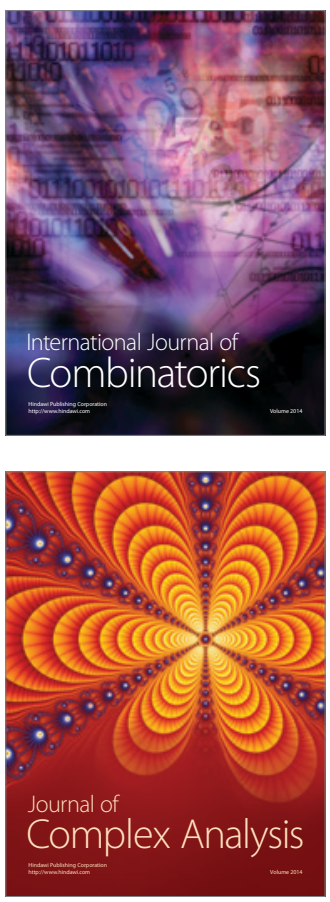

International Journal of

Mathematics and

Mathematical

Sciences
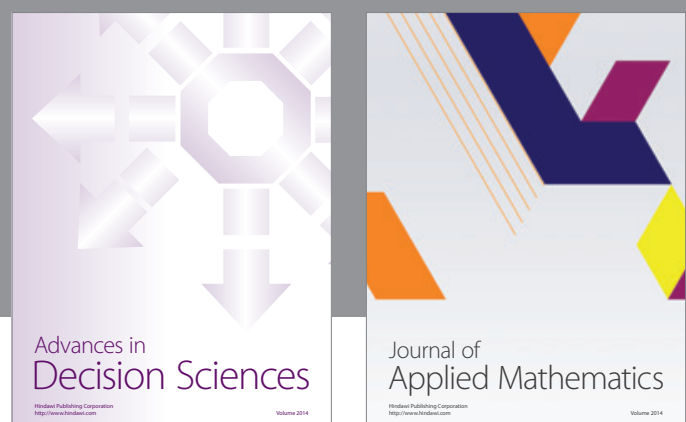

Journal of

Applied Mathematics
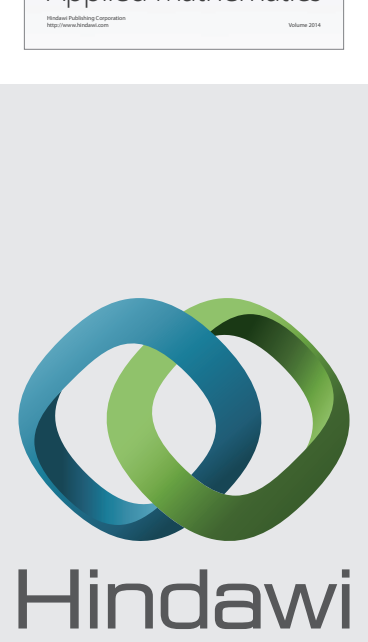

Submit your manuscripts at http://www.hindawi.com
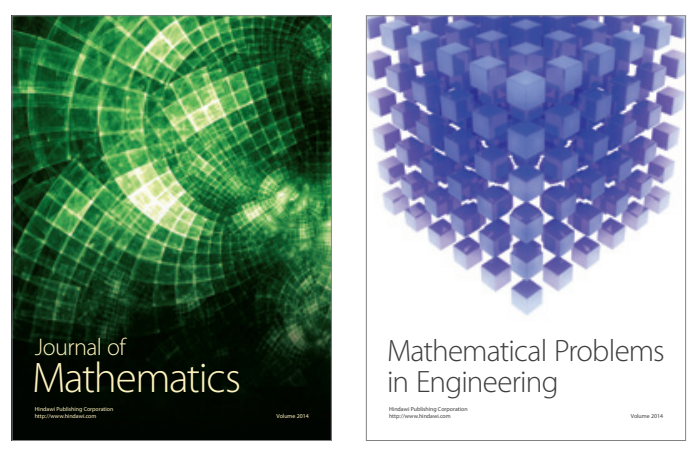

Mathematical Problems in Engineering
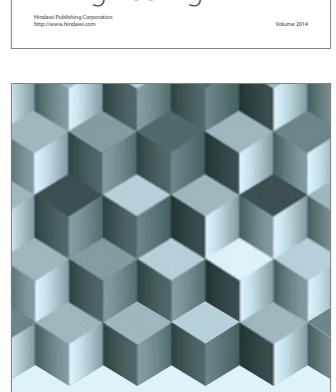

Journal of

Function Spaces
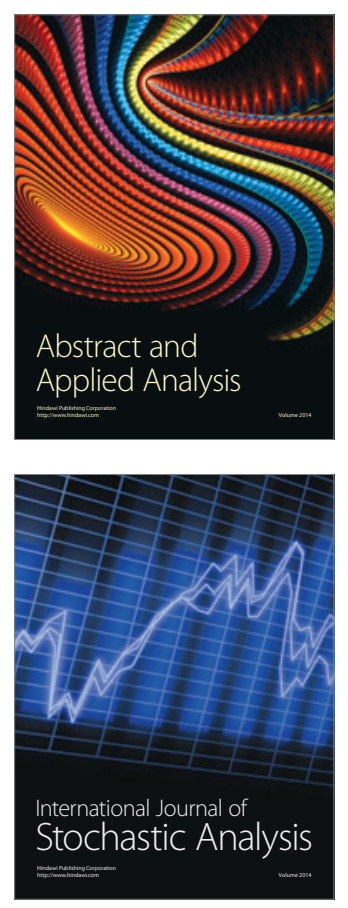

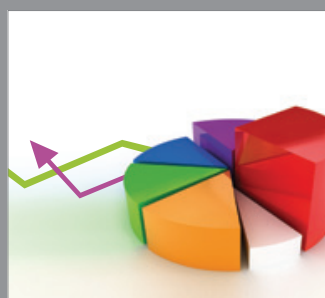

ournal of

Probability and Statistics

Promensencen
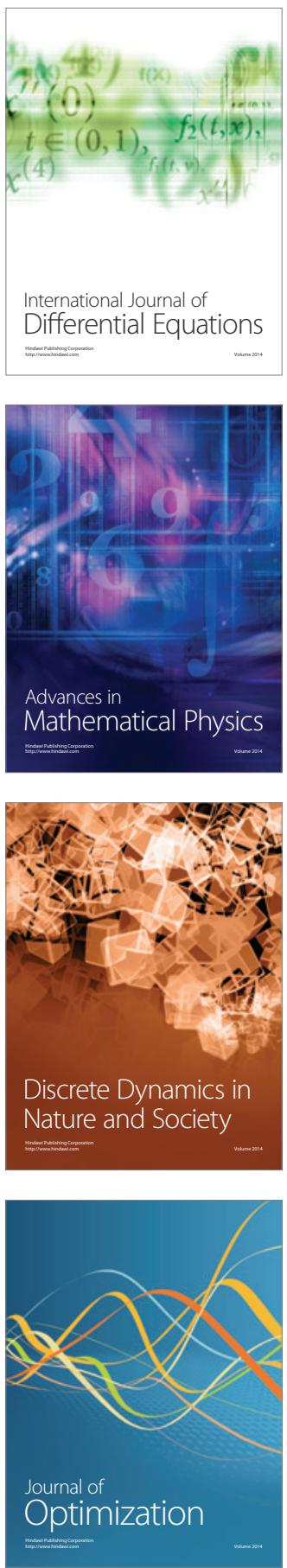